\title{
GUARDA COMPARTILHADA: ENTRE O SUPERIOR INTERESSE DA CRIANÇA E AS RESPONSABILIDADES PARENTAIS
}

\section{JOINT CUSTODY: BETWEEN THE BEST INTEREST OF CHILD AND PARENTAL RESPONSIBILITIES}

\author{
${ }^{1}$ Edgard Audomar Marx Neto \\ ${ }^{2}$ Tereza Cristina Monteiro Mafra
}

\section{RESUMO}

O presente artigo propõe a análise da aplicação da guarda compartilhada no Brasil, a partir da análise do modelo contemporâneo de atribuição de responsabilidades parentais. A premissa do trabalho é de que a afirmação do superior interesse da criança e adolescente determina a fixação de critérios de convivência familiar que garantam às crianças e adolescentes o desenvolvimento em ambiente familiar saudável. Para tanto, foram utilizados elementos sociológicos e históricos, de modo a possibilitar a compreensão das consequências da opção pelo modelo de guarda compartilhada. Por fim, por meio da análise da elementos jurisprudenciais procurou-se destacar elementos concretos que devem ser enfrentados pela preferência legislativa pela guarda compartilhada. A conclusão é de que a guarda compartilhada corresponde ao modelo que melhor atende aos interesses das crianças, podendo, diante das circunstâncias do caso concreto apuradas sob o devido processo legal, ser afastada se este interesse não for atendido.

Palavras-chave: Guarda compartilhada Superior interesse da criança, Responsabilidade parental

\begin{abstract}
This article proposes to examine the application of joint custody in Brazil, based on the analysis of the contemporary model for allocating parental responsibilities. The premise of the study is that the affirmation of the best interests of the child and adolescent determines the adoption of criteria to ensure children and adolescents the developing in healthy family environment. In order to enable an understanding of the consequences of the choice of joint custody model were used sociological and historical elements. In developing this work were also analyzed judicial precedentes. The conclusion is that joint custody corresponds to the model that best meets the interest of children but may be rejected if this interest is not met under the circumstances of the case.
\end{abstract}

Keywords/ Joint custody, Best interest of the child, Parental responsibility

\footnotetext{
${ }^{1}$ Doutor em Direito pela Universidade Federal de Minas Gerais -UFMG, Minas Gerais, MG. Professor na Universidade Federal de Minas Gerais, UFMG, Minas Gerais, MG, Brasil. E-mail: edgardmarx@gmail.com.

${ }^{2}$ Doutora em Direito pela Universidade Federal de Minas Gerais, UFMG, Minas Gerais, MG, Brasil. Professora no Instituto Brasiliense de Direito Público, IDP, Brasília, DF, Brasil. E-mail: tereza.c.mafra@terra.com.br.
} 


\section{INTRODUÇÃO}

A definição da guarda compartilhada como modelo preferencial de gestão de cuidado com os filhos menores na dissolução do relacionamento parental ou quando os pais não estejam casados ou vivam em união estável, estabelecida pela Lei n. 13.058/2014, tem trazido uma série de dúvidas no direito brasileiro.

Por conta desta realidade, o presente artigo propõe a análise da aplicação da guarda compartilhada no Brasil, a partir da análise do modelo contemporâneo de atribuição de responsabilidades parentais.

A premissa do trabalho é de que a afirmação do superior interesse das crianças e adolescentes determina a fixação de critérios de convivência familiar que garantam às crianças e adolescentes o desenvolvimento em ambiente familiar saudável.

Para tanto, foram utilizados elementos sociológicos e históricos, de modo a possibilitar a compreensão das consequências da opção pelo modelo de guarda compartilhada.

Por fim, por meio da análise da elementos jurisprudenciais procurou-se destacar elementos concretos que devem ser enfrentados pela preferência legislativa pela guarda compartilhada.

A conclusão é de que a guarda compartilhada corresponde ao modelo que melhor atende aos interesses das crianças, podendo, diante das circunstâncias do caso concreto apuradas sob o devido processo legal, ser afastada se este interesse não for atendido.

\section{A DEMOCRACIA DAS EMOÇÕES E A DIREÇÃO CONJUNTA DA FAMÍLIA: LINHAS GERAIS SOBRE A INFLUÊNCIA DOS DIREITOS FUNDAMENTAIS NO DIREITO DE FAMÍLIA}

$\mathrm{O}$ século $\mathrm{XX}$ trouxe grandes evoluções científicas, duas guerras mundiais e seus reflexos também repercutiram no âmbito familiar. A família tradicional, cuja principal missão era assegurar a transmissão de poder e de patrimônio, perpetuada por alianças entre patriarcas, como "verdadeira transposição da monarquia de direito divino", deu lugar à família contemporânea ou pós-moderna, "receptáculo de uma lógica afetiva", "que une, ao longo de uma duração relativa, dois indivíduos em busca de relações íntimas ou realização sexual” (ROUDINESCO, 2002, p. 19). 
Para Eduardo de Oliveira LEITE, “a segunda metade do século XX verá triunfar o amor sobre qualquer consideração de ordem prática ou utilitária", pois "as novas gerações sedebatem na solução de um dilema crucial: a manutenção de valores tradicionais e a emergência de novos valores traduzíveis nas novas experiências conjugais - amor livre, casamento aberto, família nuclear, família monoparental - num contexto geral de constante evolução científica e cultural" (1991, p. 374).

A Constituição causou uma significativa mudança de concepções. Na esteira do encadeamento de ideias que adquiriu impulso após a Segunda Guerra Mundial, a pessoa passou a ser situada no ponto central de um sistema de princípios e valores consagrados pela Constituição, que também devem ser aplicados no âmbito do Direito Privado. Ocorreu uma modificação axiológica nos vínculos jurídico-familiares, com a personalização das relações e a nova concepção da família é plural, dissolúvel e igualitária, finalisticamente orientada à promoção do livre desenvolvimento da personalidade de seus membros e como locus de realização pessoal e afetiva (FACHIN, 2000, p. 291-292; LÔBO, 2009, p. 11-15; TEPEDINO, 1999, p. 348-350). Segundo CARBONNIER: "O direito à família é uma forma de direito à felicidade, que deve ser garantido pelo Estado" (1995, p. 185-186).

Pluralismo, igualdade e liberdade são os três grandes princípios que orientaram as mais importantes transformações no direito de família (MALAURIE, AYNÈS, 2009, p. 41). A família contemporânea horizontal, igualitária e norteada para o livre desenvolvimento da personalidade de seus membros é muito diferente da família regulada pelo Código de 1916.

Quanto à pluralidade das entidades familiares, cabe destacar que, antes da Constituição de 1988, a família reconhecida e protegida pelo Estado se formava unicamente pelo casamento. A Constituição ampliou a proteção à família, reconhecendo, expressamente, três entidades familiares (casamento, união estável e família monoparental), caracterizando-se a pluralidade dos tipos ${ }^{1}$.

\footnotetext{
${ }^{1}$ O Supremo Tribunal Federal reconheceu a união entre pessoas do mesmo sexo como entidade familiar (STF, Pleno, ADI 4.277, Rel. Min. Ayres Britto, j. 05.05.2011). E o Superior Tribunal de Justiça , por maioria, autorizou o casamento entre duas mulheres (STJ, 4. T, REsp 1.183.378, Rel. Min. Luís Felipe Salomão, j. 03.06.2012).
} 
Despojado da sacralidade e da existência ligada à diversidade de sexo, na base do casamento e da união estável, como entidades familiares tipificadas na Constituição da República, está a comunhão plena de vida e não a questão do gênero, pois “a vida sexual, que costumava ser relacionada de modo absoluto com a vida matrimonial e a legitimidade, tem agora poucas, ou nenhumas, relações com elas" (GIDDENS, 2005, p. 61).

Apesar de as Constituições anteriores à de 1988 terem previsto a igualdade, tal se referia ao aspecto formal, reflexo dos ideais do liberalismo, tomada no sentido genérico de não discriminação, sem levar em conta as concretas diferenças entre as pessoas e suas posições sociais, prevalecendo a preocupação com a defesa do cidadão contra possíveis violações de seus direitos pelo Estado, em decorrência do absolutismo antecedente, tratando-se de um modelo que, segundo HABERMAS,

\begin{abstract}
parte da premissa segundo a qual a constituição do Estado de direito democrático deve repelir primariamente os perigos que podem surgir na dimensão que envolve o Estado e o cidadão, portanto nas relações entre o aparelho administrativo que detém o monopólio do poder e as pessoas privadas desarmadas. Ao passo que as relações horizontais entre as pessoas privadas, especialmente as relações intersubjetivas, não têm nenhuma força estruturadora para o esquema liberal de divisão dos poderes. Nisso se encaixa a representação positivista do direito, que o tem na conta de um sistema de regras fechado recursivamente (1997, p. 305).
\end{abstract}

A Constituição de 1988, ao tratar da família, consagrou expressamente, além da cláusula geral $^{2}$, a igualdade entre marido e mulher ${ }^{3}$ e entre os filhos ${ }^{4}$, considerando a família, base da sociedade, merecedora de especial proteção do Estado. Consagrou-se, nas palavras de Hesse, "a tarefa positiva dos poderes estatais de proteger matrimônio e família não só contra prejuízos, mas também de fomentá-los por medidas adequadas" (HESSE, 1998, p. $351)$.

O enunciado constitucional de que homens e mulheres são iguais em direitos e obrigações corresponde a uma "lex generalis em relação às normas especiais sobre igualdade" (ALEXY, 2008, p. 412). A fórmula clássica de que o igual deve ser tratado igualmente e o desigual, desigualmente não traduz somente um princípio universalizante, dirigido ao conteúdo das normas, inclui um dever formal, que vincula o legislador, porque há um dever de igualdade não apenas na aplicação, mas também na criação do direito (ALEXY, 2008, p. 395). A isonomia "quer não só eliminar normas jurídicas, que unem vantagens e desvantagens a caracteres sexuais, mas, para o futuro, realizar igualdade de direitos dos sexos" (HESSE, 1998, p. 333). 
Houve mudanças no comportamento e nas expectativas das relações afetivas e sexuais, com a família partilhando algumas características da esfera pública da democracia, quais sejam: “discussão pública de problemas isenta de violência e autoridade negociada em vez de dada por tradição" (GIDDENS, 2005, p. 103). A igualdade nas relações conjugais foi elevada à categoria de direito humano (LORENZETTI, 1998, p. 134).

O princípio da igualdade substancial, previsto no art. 227, $\S 6^{\circ}$, da Constituição, estabelece que "os filhos, havidos ou não da relação do casamento, ou por adoção, terão os mesmos direitos e qualificações, proibidas quaisquer designações discriminatórias relativas à filiação". Além de impedir diferenças de tratamento entre o filhos em decorrência da sua origem biológica ou não, a isonomia obsta quaisquer distinções fundadas na espécie de vínculo que une os pais (se casados, ou em união estável).

\begin{abstract}
Concretamente, é possível extrair da ratio constitucional uma opção pela responsabilidade familiar como princípio norteador das relações familiares, alinhando-se com as diretrizes do direito internacional, atestadas na Declaração Universal dos Direitos dos Homens (1948) e na Convenção Interamericana de Direitos Humanos, o Pacto de San José da Costa Rica (ROSENVALD, FARIAS, 2015, p. 102).
\end{abstract}

Os filhos, nas disputas judiciais entre seus genitores, passaram de objetos das controvérsias a sujeitos de direitos e destinatários principais da prestação jurisdicional, que deve ser norteada pelo princípio do superior interesse do menor (the best interest of the child) e pelo princípio da proteção integral, de modo que a solução dos conflitos deve ser pautada pela busca da efetividade dos direitos fundamentais da criança e do adolescente.

Destaca-se, também, a direção conjunta da família, corolário da igualdade, expressa na Constituição (art. 226, $\S 5^{\circ}$ ) e reproduzida no art. 1.511, que inaugura a regulamentação do direito de família no Código Civil. Por força do princípio da igualdade, pai e mãe são investidos, em idêntica posição, no denominado poder familiar. O poder familiar constitui um conjunto de direitos e poderes que os pais têm em relação à pessoa e bens dos seus filhos menores e não emancipados, para o cumprimento dos seus deveres de

\footnotetext{
${ }^{2}$ Art. $5^{\circ}$. Todos são iguais perante a lei, sem distinção de qualquer natureza, garantindo-se aos brasileiros e aos estrangeiros residentes no País a inviolabilidade do direito à vida, à liberdade, à igualdade, à segurança e à propriedade, nos termos seguintes: I - homens e mulheres são iguais em direitos e obrigações, nos termos desta Constituição.

3 Art. 226. A família, base da sociedade, tem especial proteção do Estado. $\S 5^{\circ}$. Os direitos e deveres referentes à sociedade conjugal são exercidos igualmente pelo homem e pela mulher.

${ }^{4}$ Art. $227, \S 6^{\circ}$ Os filhos, havidos ou não da relação do casamento, ou por adoção, terão os mesmos direitos e qualificações, proibidas quaisquer designações discriminatórias relativas à filiação.
} 
cuidado e promoção do livre desenvolvimento da personalidade das crianças e adolescentes, competindo-lhes assegurar, com absoluta prioridade, a efetivação dos direitos referentes à vida, à saúde, à alimentação, à educação, ao esporte, ao lazer, à profissionalização, à cultura, à dignidade, ao respeito, à liberdade e à convivência familiar e comunitária (art. 4 ${ }^{\text {, }}$, Lei n. 8.069/1990 - Estatuto da Criança e do Adolescente).

A liberdade se traduziu pela maior autonomia conferida às pessoas na tomada de decisões no âmbito da família, especialmente no tocante à maior autodeterminação no término dos relacionamentos conjugais e pela simplificação das formas de dissolução docasamento. A Constituição consagra o princípio da liberdade de planejamento familiar fundado nos princípios da dignidade da pessoa humana e da paternidade responsável ${ }^{5}$.

A democracia das emoções não implica falta de disciplina ou ausência de respeito, como esclarece GIDDENS:

Falar do fomento da democracia emocional não significa ser fraco em questões de família ou na defesa das políticas de família perante as entidades públicas. A democracia implica aceitação de todos os direitos e obrigações que tenham sanção legal. (...) A igualdade sexual não é apenas um princípio fundamental da democracia. Também é relevante para a felicidade e para a realização das pessoas $(2005,67-68)$.

As possibilidades eletivas emergentes ("p. ex., a mobilidade profissional dos cônjuges em direções divergentes, a repartição do trabalho doméstico e do cuidado com as crianças, o tipo de método anticoncepcional, a sexualidade"), acendem a conscientização dos conflitos na relações familiares (BECK, 2010, p. 162).

Sobre a história do amor no século XXI, Mary DEL PRIORE concluiu que "a liberdade amorosa tem contrapartidas: a responsabilidade e a solidão" (2006, p. 320):

\footnotetext{
O casamento, fundado sobre o amor, não é mais obrigatório e ele escapa às estratégias religiosas e familiares; o divórcio não é mais vergonhoso e os cônjuges têm o mesmo tratamento perante a lei. A realização pessoal coloca-se acima de tudo: recusamos a frustração e a culpa. Mas tudo isso são conquistas ou armadilhas? Os historiadores de amanhã o dirão (DEL PRIORE, 2006, p. 312).
}

Como lecionava Virgílio de Sá PEREIRA: “A família deve portanto constituir-se sob um regime de liberdade, que exclua a tirania, e de autoridade, que exclua a anarquia. Estas fórmulas de liberdade e de autoridade não são, aliás, categorias absolutas, mas relativas, variáveis conforme o ritmo geral da evolução à qual se submete a família como todas as instituições sociais" (2008, p. 13). 
Diante destes novos paradigmas, a tendência de se atribuir, isoladamente, a guarda dos filhos menores a um só dos pais vem se abrandando, buscando-se evitar o desequilíbrio quanto aos direitos parentais, em que a notória preferência reconhecida à mãe mostra-se, em princípio, contrária à previsão constitucional de igualdade entre o homem e a mulher (LEITE, 2003, p. 258-259).

\title{
3 NOVOS PAPÉIS E RESPONSABILIDADES
}

Em setembro de 2014, a revista Isto É noticiou, de acordo com dados relativos ao ano de 2012 , que em $87,10 \%$ dos casos as guardas foram atribuídas unilateralmente às mães, enquanto 5,38\% concedidas aos pais, remanescendo 5,95\% de decisões judiciais de guardas compartilhadas (BRANDALISE, 2014).

A Lei n. 13.058/2014 alterou o Código Civil, que passou a prever que "Quando não houver acordo entre a mãe e o pai quanto à guarda do filho, encontrando-se ambos os genitores aptos a exercer o poder familiar, será aplicada a guarda compartilhada, salvo se um dos genitores declarar ao magistrado que não deseja a guarda do menor" (art. $\left.1.584, \S 2^{\circ}\right)$.

Ou seja, apesar de a preferência legal ser pelo modelo de guarda compartilhada, ainda é preponderante o deferimento majoritário de guarda exclusiva à mulher, preservando-se a perspectiva de que os cuidados e educação da prole são de responsabilidade exclusivamente feminina.

Todavia, esta é uma perspectiva em mutação:

\begin{abstract}
Atualmente, há uma nova configuração de paternidade e de maternidade surgindo, pois o bebê e a criança não são mais compreendidos como sendo de responsabilidade exclusivamente feminina, no que tange aos cuidados e à educação (Goetz \& Vieira, 2009; Piccinini, Levan-dowiski, Gomes, Lindenmeyer, \& Lopes, 2009). Mesmo quando as mães são as principais responsáveis pela maior parte das tarefas domésticas, os pais estão participando com maior frequência, o que reflete uma reelaboração das atribuições masculinas frente à paternidade (Genesoni \& Tallandini, 2009). Muitos pais relacionam-se com seus filhos cotidianamente, apreciando a companhia destes e tornando-se figuras centrais em suas vida (Cia \& Barham, 2009) (DESSEN, OLIVEIRA, 2014).
\end{abstract}

\footnotetext{
${ }^{5}$ Art. 226. A família, base da sociedade, tem especial proteção do Estado. § 7º. Fundado nos princípios da dignidade da pessoa humana e da paternidade responsável, o planejamento familiar é livre decisão do casal, competindo ao Estado propiciar recursos educacionais e científicos para o exercício desse direito, vedada qualquer forma coercitiva por parte de instituições oficiais ou privadas.
} 
Conforme explicam Maria Auxiliadora DESSEN e Maíra Ribeiro de OLIVEIRA, "independentemente das mudanças sociais que ocorreram, particularmente em meados do século XX, alterando a compreensão do que significa ser pai, na atualidade, e a própria representação social da paternidade (Souza \& Benetti, 2009), o tornar-se pai continua sendo um momento importante e decisivo no desenvolvimento do indivíduo e da família" (2014).

Deste modo, qualquer discussão sobre os modelos de guarda deve passar, inevitavelmente, pela discussão dos papéis desempenhados pelos genitores em relação a seus filhos

\section{SUPERIOR INTERESSE DA CRIANÇA}

Ao lado das discussões sobre o papel dos genitores - e mesmo acima dele - deve ser verificado, na determinação das situações de guarda, o atendimento ao superior interesse de crianças e adolescentes.

Assim está previsto no art. 227 do texto constitucional, com redação determinada pela Emenda Constitucional n. 65/2010: “Art. 227. É dever da família, da sociedade e do Estado assegurar à criança, ao adolescente e ao jovem, com absoluta prioridade, o direito à vida, à saúde, à alimentação, à educação, ao lazer, à profissionalização, à cultura, à dignidade, ao respeito, à liberdade e à convivência familiar e comunitária, além de colocá-los a salvo de toda forma de negligência, discriminação, exploração, violência, crueldade e opressão".

Em idêntico sentido, o Estatuto da Criança e do Adolescente (Lei n. 8.069/90) determina que "a criança e o adolescente gozam de todos os direitos fundamentais inerentes à pessoa humana, sem prejuízo da proteção integral de que trata esta Lei, assegurando-se-lhes, por lei ou por outros meios, todas as oportunidades e facilidades, a fim de lhes facultar o desenvolvimento físico, mental, moral, espiritual e social, em condições de liberdade e de dignidade" (art. $3^{\circ}$ ).

Não é diversa a previsão da Convenção sobre os Direitos da Criança, incorporada ao direito brasileiro por meio do Decreto n. 99.710/90: “Todas as ações relativas às crianças, levadas a efeito por instituições públicas ou privadas de bem estar social, tribunais, autoridades administrativas ou órgãos legislativos, devem considerar, primordialmente, o interesse maior da criança" (art. 3.1). 
Em síntese, "há uma evidência a destacar: todas as convenções têm um mesmo objetivo, todas as regras que elas contêm são elaboradas em função de um mesmo critério, todos os direitos reconhecidos à criança na sociedade e na família são orientados em uma mesma direção: o interesse da criança" (FULCHIRON, 1996, p. 21).

Hugues FULCHIRON destaca que, apesar da previsão generalizada do melhor interesse da criança em textos normativos, prevalece a indicação de direitos específicos, como o direito à convivência familiar e de ter sua vida protegida, antes e depois do nascimento, de maneira a se garantir ao menos o mínimo a ser preservado (1996, p. 22).

A identificação do melhor interesse da criança acaba sendo conduzida, na maioria das vezes, pelo critério da decisão razoável naquele caso. Ou, inversamente, definido em termos dos desejos de seus pais (DWORKIN, 1988, p. 92).

Em posição diferenciada, Martin GUGGENHEIM propõe que não é correta a identificação entre a atribuição de direitos às crianças e a diminuição da extensão do poder paterno. Embora a bandeira dos movimentos em prol dos direitos infantis tenha sido a diminuição dos poderes concedidos aos pais - como a possibilidade de infligir castigos físicos, por exemplo - não se consegue precisar se essas mudanças trouxeram benefícios às crianças (2005, p. 245).

A prática do direito norte-americano tem buscado a realização do melhor interesse a partir das variações de quatro fatores: 1. "a interação e inter-relacionamento da criança com seu pai [parent] ou pais, com seus irmãos, e qualquer outra pessoa que possa afetar significativamente omelhor interesse da criança"; 2. "o ajustamento da criança ao seu lar, escola e comunidade"; 3. "os desejos da criança em relação à sua guarda"; e 4. "a saúde física e mental de todos os indivíduos envolvidos" (GUGGENHEIM, 2005, p. 152). A popularidade de tal conceito, segundo GUGGENHEIM, decorre principalmente por elevar os interesses da criança acima daqueles dos adultos. Todavia, essa superioridade retórica pode ser facilmente posta de lado (2005, p. 153). Em uma separação consensual, por exemplo, os pais podem decidir a guarda e a regulamentação da visita contra o interesse da criança e essa situação afigurar-se judicialmente irrelevante, a despeito da necessária intervenção dos atores envolvidos (Magistratura e Ministério Público) em favor da efetivação dos direitos das crianças e adolescentes.

Já Alejandra de LAMA AYMÁ propõe três dados para identificar o melhor interesse da criança: os seus desejos, a aprendizagem de determinados valores e normas sociais e a participação e audiência do menor. Diante desses três parâmetros, a atuação do c) (i) (8) 
responsável deve ser guiada, ainda, pela projeção dos efeitos do momento para o futuro (2004, 199-204).

A partir dessas ponderações, verifica-se que não existe uma regra já organizada do que seja o melhor interesse da criança (SILVA PEREIRA, 1999). Todavia, a ausência de um conteúdo acabado não dispensa os pais e responsáveis de procurar sua realização na vida familiar e o Judiciário de fazê-lo na sua atuação. Como adverte Rousseau, "as verdadeiras necessidades são muito limitadas nas crianças como nos homens, e deve-se olhar mais a duração do bem-estar do que o bem-estar de um só momento" (2006, p. 493).

O reconhecimento da aplicabilidade do princípio constitucional do superior interesse da criança à matéria de definição de guarda levou o Tribunal de Justiça do Estado do Rio de Janeiro, antes mesmo da edição da Lei n. 13.058/2014, a atribuir a guardacompartilhada à genitora e ao avô materno, reconhecendo que em demanda envolvendo interesse de menor deve prevalecer a diretriz legal lançada pelo Estatuto da Criança e do Adolescente (ECA): "Proteção integral à criança e ao adolescente como pessoa humana em desenvolvimento e como sujeito de direitos civis, humanos e sociais, garantidos, originariamente, na CRFB/88” (TJRJ, 20 Câmara Cível, Apelação 0006376-

81.2011.8.19.0205, Rel. Des. Conceição Aparecida Mousnier Teixeira de Guimarães Pena, j. 07.01.2014).

Ou seja, a premissa da guarda compartilhada é o interesse da criança, não o interesse dos pais. Pode ser que, diante da realidade do caso, o regime de guarda compartilhada se mostre prejudicial à criança.

Neste sentido, decidiu o Superior Tribunal de Justiça que

\begin{abstract}
Ao exercício da guarda sobrepõe-se o princípio do melhor interesse da criança e do adolescente, que não se pode delir, em momento algum, porquanto o instituto da guarda foi concebido, de rigor, para proteger o menor, para colocá-lo a salvo de situação de perigo, tornando perene sua ascensão à vida adulta. Não há, portanto, tutela de interesses de uma ou de outra parte em processos deste jaez; há, tão-somente, a salvaguarda do direito da criança e do adolescente, de ter, para si prestada, assistência material, moral e educacional, nos termos do art. 33 do ECA (STJ, 3. T., REsp 964.836, Rel. Min. Nancy Andrighi, j. 02.04.2009).
\end{abstract}

Em delicado processo de atribuição de guarda de criança de seis anos, submetido a grave sofrimento emocional com o processo de separação dos pais, que, cada qual a sua maneira, pretendiam educá-lo, com caracterização recíproca de tentativas de alienação 
parental, o TJRS acabou por privilegiar a guarda unilateral, no interesse da criança: "A guarda deve atender, primordialmente, ao interesse do menor, o qual demonstrou sofrimento quando do exercício da guarda compartilhada, devendo ser mantida a guarda com a genitora" (Apelação Cível No 70062260252, Sétima Câmara Cível, Tribunal de Justiça do RS, Relator: Jorge Luís Dall'Agnol, Julgado em 17/12/2014). A opção pela mãe deveu-se à sua adesão ao programa de orientação psicológica, que foi recusado pelo pai.

\section{GUARDA E CUIDADO: OS DIFERENTES MODELOS DE GUARDA}

A introdução da guarda compartilhada no ordenamento jurídico positivo brasileiro foi uma grande conquista e também um meio de conferir eficácia ao princípio da igualdade entre homens e mulheres, no tocante à guarda dos filhos menores.Entretanto, como assevera Eduardo Ponte BRANDÃO, "os novos direitos da infância e a isonomia entre o homem e a mulher abriram um novo front de guerra. As disputas familiares são uma extensão do campo de batalha da política de gênero. Os litígios de guarda e visita são micro-batalhas que formam subjetividades" (2010).

Nesse cenário de igualdade, porém, a perda da primazia feminina no exercício da guarda unitária dos filhos, como aspecto negativo, deve-se mencionar o recrudescimento do fenômeno da alienação parental.

Antes, porém de se analisar a dinâmica da guarda compartilhada, necessário retomar as distinções entre as possibilidades de regulamentação da guarda, ou seja, diferenciar entre guarda unilateral, alternada e compartilhada.

Guarda unilateral definiu-se como aquela atribuída a um só dos genitores, ou a alguém que o substitua e, por guarda compartilhada compreende-se a responsabilização conjunta e o exercício de direitos e deveres, do pai e da mãe, que não vivam sob o mesmo teto, concernentes ao poder familiar dos filhos comuns.

A previsão na lei, expressamente, do significado atribuído às espécies de guarda por ela reguladas tem a inegável utilidade de evitar interpretações díspares e confusão conceitual, ante a existência de múltiplos modelos, tais como a unilateral, alternada e compartilhada.

A guarda unilateral dá-se quando o menor tem uma moradia fixa, em companhia de um dos pais, recebendo a visita periódica daquele que não detém a guarda. Para Eduardo de 
Oliveira LEITE, a tendência dos Tribunais no sentido de atribuir, sistematicamente, à mãe o exercício da guarda, reservando ao pai somente as visitas, levou a distorções: tanto há o abandono dos filhos por pais desmotivados pela ausência dos mesmos, como também a revolta dos genitores que não mais admitem ser relegados a um papel “secundário" (2003, p. 260-261).

A guarda alternada - equivocada e freqüentemente confundida com a compartilhada - é aquela na qual os genitores dividem, em partes iguais, o tempo em companhia do filho e cujos períodos se alternam em dias, semanas, meses ou anos. Cada um dos pais exerce a guarda, alternadamente, com todos os atributos que lhe são inerentes. De acordo com a psicanalista Françoise DOLTO, as guardas alternadas não asseguram ao "filho-joguete" um continuum afetivo, espacial e tampouco social, prejudicando o desenvolvimento da criança $(1989$, p. 73-74).

Diversamente, a guarda compartilhada refere-se a um tipo de guarda, na qual o pai e a mãe dividem a responsabilidade legal sobre os filhos, ao mesmo tempo, e compartilham as obrigações pelas decisões importantes a eles relativas.

Trata-se de um cuidar dos filhos, concedido aos pais, que devem atuar em cooperação, com respeito e igualdade, sempre priorizando o bem-estar do menor.

A guarda compartilhada originou-se na Common Law (joint custody), desenvolveu-se no Canadá e Estados Unidos, e instaurou-se na Europa, assimilada pela França, a partir de 1976 (GRISARD FILHO, 2002, p. 123-124).

O exercício compartilhado da autoridade parental, porém, não se estende à guarda física e dela independe. Ou seja, o menor poderá ter sua moradia estabelecida com o pai ou a mãe. Compartilhadas serão as prerrogativas na tomada de decisões acerca dos filhos, não importando quem deterá a custódia física, como explica Rolf MADALENO (2008, p. 357).

Pode-se concluir que há um exercício simultâneo de guarda intelectual e uma guarda material sucessiva. Em virtude da simultaneidade da guarda intelectual, os pais devem determinar, conjuntamente, o modo de vida e as grandes decisões concernentes à educação, à saúde e aos demais aspectos relativos aos filhos (PERDRIX, 2010, p. 191192).

Com a mudança introduzida no Código Civil, a guarda, unilateral ou compartilhada, poderá ser fixada, por consenso ou por determinação judicial, para prevalecer por determinado período, considerada a faixa etária do filho e outras condições de seu 
interesse. E, quando não houver acordo entre a mãe e o pai quanto à guarda do filho, será aplicada, sempre que possível, a guarda compartilhada.

Do parecer da Comissão de Constituição, Justiça e Cidadania, favorável ao Projeto de Lei n. 117/2013, consta:

A guarda conjunta garante, de forma mais efetiva, a permanência da vinculação mais estrita de ambos os pais na formação e na educação dos filhos, que a simples visitação dá espaço. O compartilhar da guarda dos filhos é o reflexo mais fiel do que se entende por poder familiar. A participação no processo de desenvolvimento integral dos filhos leva à pluralização das responsabilidades, estabelecendo verdadeira democratização de sentimentos (RAUPP, 2014).

O legislador recomenda a guarda compartilhada, que pressupõe o exercício da autoridade parental de modo harmônico, ou, pelo menos, em cooperação pelos pais.6 A dinâmica da guarda compartilhada

A nova orientação, decorrente da Lei n. 13.058/2014, já pode ser verificada nos Tribunais brasileiros. Se antes prevalecia entendimento mais restritivo à concessão da guarda compartilhada, agora esta deve ser buscada mesmo em situações de adversidade. Veja-se, por exemplo, o posicionamento do Tribunal de Justiça de Minas Gerais. Em outubro de 2014 o Tribunal negou apelo do Ministério Público para tornar compartilhada a guarda unilateral concedida a um dos genitores por meio de acordo (divórcio consensual) nos seguintes termos:

APELAÇÃO CÍVEL - DIVÓRCIO - GUARDA DOS FILHOS -
INCONFORMISMO DO MINISTÉRIO PÚBLICO - PRETENSÃO DE
GUARDA COMPARTILHADA - INEXISTENCIA DE ELEMENTOS
PARA O DEFERIMENTO - MANUTENÇÃO DA GUARDA
UNILATERAL ACORDADA ENTRE OS DIVORCIANDOS E
HOMOLOGADA NA SENTENÇA - INTELIGÊNCIA DO ART. 1584, § $2^{\circ}$
DO CPC - DECISÃO MANTIDA. 1. Conforme entendimento remansoso na
doutrina e na jurisprudência, a chamada guarda compartilhada é subsidiária à
guarda acordada entre os pais(CC, art. 1284, § $2^{\circ}$ ), e só deve ser instituída
quando for a vontade dos genitores. Além disso, é necessário que exista um
amistoso relacionamento e potencial capacidade de diálogo para o exercício
conjunto da guarda. 2. Uma vez que a guarda unilateral das filhas foi alvo de
acordo entre os genitores e homologada em Juízo, infundada a pretensão
recursal, notadamente se o genitor não demonstra interesse em compartilhar a
guarda, e se o pleito não vem respaldado em estudos social e/ou psicossocial
indicativo da pertinência da medida. 3. Recurso não provido. (TJMG -
Apelação Cível 1.0396.12.002245-6/001, Relator(a): Des.(a) Raimundo
Messias Júnior , 2a CÂMARA CÍVEL, julgamento em 08/10/2014,
publicação da súmula em 17/10/2014)

Importante destacar que, no julgamento, ficou consignado de modo expresso que "Se em algum momento os genitores amadurecerem para a necessidade de modificação da forma de guarda, é certo que não haverá nenhum impedimento para a alteração para o 
outro genitor ou adoção da guarda compartilhada, desde que resguardado o interesse das menores".

A guarda compartilhada não pode significar a divisão da criança, tal como referido na passagem bíblica que expressa a sabedoria do Rei Salomão (1 Reis 3, 16-28). Na hipótese de discussão sobre guarda de menor de 11 meses, laudo psicológico reconheceu como patológica a "solicitude exagerada do pai com relação à saúde e cuidados com a criança", recomendando inclusive a realização de acompanhamento psiquiátrico. É interessante notar que, conforme decidido pelo TJRJ no caso, a guarda compartilhada "não se caracteriza por uma divisão matemática das horas semanais entre duas residências, mas por uma cooperação dos pais nos cuidados dos filhos". Pelo contrário, a tentativa de cronometrar a convivência seria prejudicial à criança, verificadaa "movimentação constante entre duas residências, durante o período escolar, que pode gerar instabilidade e insegurança ao menor, especialmente quando os pais não se entendem" (TJRJ, 10 Câmara Civil, Apelação 0013868-83.2009.8.19.0209, Rel. Des. Gilberto Dutra Moreira, j. 07.11.2012).

Se a guarda compartilhada significa a cooperação dos pais nos cuidados para com os filhos, nem mesmo a residência em localidades distintas pode impedir seu deferimento. Se é certo que a criança não pode viver, simultaneamente, em dois lugares, o estabelecimento da guarda compartilhada nestas situações deve valorizar os períodos possíveis, notadamente férias e feriados prolongados. Ou seja, o deferimento da guarda compartilhada, na hipótese, ressalta o exercício conjunto da parentalidade, nas condições possíveis.

Neste sentido, o TJRS determinou que o regime de guarda compartilhada não importa a alternância de residências, mas deve privilegiar a referência de moradia. Assim, destacase parte da decisão:

\footnotetext{
A chamada guarda compartilhada não consiste em transformar a filha em objeto, que fica a disposição de cada genitor por um determinado período, mas uma forma harmônica ajustada pelos genitores, que permita à filha desfrutar tanto da companhia paterna como da materna, num regime de visitação bastante amplo e flexível, mas sem que a infante perca seus referenciais de moradia. (Apelação Cível No 70062745229 , Sétima Câmara Cível, Tribunal de Justiça do RS, Relator: Sérgio Fernando de Vasconcellos Chaves, Julgado em 17/12/2014)
}

Há que se ressaltar que, assente no princípio constitucional do superior interesse da criança, a jurisprudência vinha reconhecendo a necessidade de apuração das condições de cada caso para a determinação do regime de guarda. Veja-se, por exemplo, decisão 
do TJRS: "Inexiste urgência a autorizar em grau recursal o pretendido estabelecimento da guarda compartilhada, para o que é necessária a verificação de um perfeito entendimento entre os genitores a esse respeito, o que reclama investigação na espécie, devendo esse questionamento ser levado à apreciação na origem" (Agravo de Instrumento No 70062375464, Oitava Câmara Cível, Tribunal de Justiça do RS, Relator: Ricardo Moreira Lins Pastl, Julgado em 05/03/2015).

Por fim, não se pode olvidar que a atribuição de guarda compartilhada não constitui óbice à fixação de alimentos, uma vez que a assunção de cuidado e divisão de responsabilidades não se confunde com o critério de possibilidade para fixação de obrigação alimentar.

\section{Conclusão}

Os filhos, nas disputas judiciais entre seus genitores, passaram de objetos das controvérsias a sujeitos de direitos e destinatários principais da prestação jurisdicional, que deve ser norteada pelo princípio do superior interesse do menor (the best interest of the child) e pelo princípio da proteção integral, de modo que a solução dos conflitos deve ser pautada pela busca da efetividade dos direitos fundamentais da criança e do adolescente. Diante destes novos paradigmas, a tendência de se atribuir, isoladamente, a guarda dos filhos menores a um só dos pais vem se abrandando, buscando-se evitar o desequilíbrio quanto aos direitos parentais.

Por força do princípio da igualdade, pai e mãe são investidos, em idêntica posição, no denominado poder familiar. O poder familiar constitui um conjunto de direitos e poderes que os pais têm em relação à pessoa e bens dos seus filhos menores e não emancipados, para o cumprimento dos seus deveres de cuidado e promoção do livre desenvolvimento da personalidade das crianças e adolescentes, competindo-lhes assegurar, com absoluta prioridade, a efetivação dos direitos referentes à vida, à saúde, à alimentação, à educação, ao esporte, ao lazer, à profissionalização, à cultura, à dignidade, ao respeito, à liberdade e à convivência familiar e comunitária (art. $4^{\circ}$, Lei n. 8.069/1990 - Estatuto da Criança e do Adolescente).

Neste panorama, a guarda compartilhada refere-se a um tipo de guarda, na qual o pai e a mãe dividem a responsabilidade legal sobre os filhos, ao mesmo tempo, e compartilham as obrigações pelas decisões importantes a eles relativas. 
A premissa da guarda compartilhada é o interesse da criança, não o interesse dos pais. Pode ser que, diante da realidade do caso, o regime de guarda compartilhada se mostre prejudicial à criança.

\section{Referências bibliográficas}

ALEXY, Robert. Teoria dos direitos fundamentais. Trad. Virgílio Afonso da Silva. São Paulo: Malheiros, 2008.

BECK, Ulrich. Sociedade de risco: rumo a uma outra modernidade. Trad. Sebastião Nascimento. São Paulo: Ed. 34, 2010.BRANDALISE, Camila. No caminho da guarda compartilhada. Revista Isto É independente, set. 2014. Disponível em: $<$ http://www.istoe.com.br/reportagens/382249_

NO+CAMINHO+DA+GUARDA+COMPARTILHADA>. Acesso em 16.08.2015.

BRANDÃO, Eduardo Ponte. Por uma ética e política da convivência: uma breve exame da "Síndrome de Alienação Parental" à luz da genealogia de Foucault. Disponível em < http://www.ibdfam.org.br/?artigos\&artigo=555>. Acesso em 28.08.2010.

CARBONNIER, Jean. A chacun sa famille, à chacun son droit. Essais sur les lois. 2. éd., 1995.

DEL PRIORE, Mary. História do amor no Brasil. São Paulo: Contexto, 2006.

DESSEN, Maria Auxiliadora; OLIVEIRA, Maíra Ribeiro de. Envolvimento paterno durante o nascimento dos filhos: pai "real" e "ideal" na perspectiva materna. www.scielo.br/scielo.php?script=sci_arttext\&pid=S010279722013000100020.

Disponibilizado em 30.07.2014.

DOLTO, Françoise. Quando os pais se separam. (trad. Vera Ribeiro). Rio de Janeiro: Jorge Zahar Editor, 1989.

DWORKIN, Gerald. The Theory and Practice of Autonomy. Cambridge: Cambridge University Press, 1988.

FACHIN, Luiz Edson. Teoria crítica do direito civil. Rio de Janeiro: Renovar, 2000.

FULCHIRON, Hugues. Les Conventions internationales: présentation sommaire. In: RUBELLIN-DEVICHI, Jacqueline \& FRANK, Rainer (Dir.). L'enfant et les conventions internationales. Lyon: Presses universitaires de Lyon, 1996:19-33.

GIDDENS, Anthony. A terceira via: reflexões sobre o impasse político atual e o futuro da social-democracia. Trad. Maria Luiza X. de A. Borges. Rio de Janeiro: Record, 2005.

GIDDENS, Anthony. O mundo na era da globalização. Trad. Saul Barata. 5. ed., Lisboa: Editorial Presença, 2005.

GRISARD FILHO, Waldyr. Guarda Compartilhada: um novo modelo de responsabilidade parental. 2. ed. São Paulo: RT, 2002. 
GUGGENHEIM, Martin. What's Wrong with Children's Rights. Cambridge - London: Harvard University Press, 2005.

HABERMAS, Jürgen. Direito e democracia: entre faticidade e validade. V. 1, trad. Flávio Beno Siebeneichler. Rio de Janeiro: Tempo Brasileiro, 1997.

HESSE, Konrad. Elementos de direito constitucional da República Federal da Alemanha. Trad. Luís Afonso Heck. Porto Alegre: Sergio Antonio Fabris, 1998.

LAMA AYMÁ, Alejandra de. La Protección de los Derechos de la Personalidad del Menor de Edad [Tesi Doctoral]. Barcelona: Universitat Autònoma de Barcelona, 2004.

LEITE, Eduardo de Oliveira. Famílias Monoparentais: A situação jurídica de pais e mães separados e dos filhos na ruptura da vida conjugal. 2. ed. São Paulo: RT, 2003.

LEITE, Eduardo de Oliveira. Tratado de Direito de Família: Origem e evolução do casamento. Curitiba: Juruá, 1991.

LÔBO, Paulo. Direito Civil: Famílias. 2. ed. São Paulo: Saraiva, 2009.

LORENZETTI, Ricardo Luis. Fundamentos do direito privado. Trad. Vera Maria Jacob de Fradera. São Paulo: RT.

MADALENO, Rolf. Curso de Direito de Família. Rio de Janeiro: Forense, 2008.

MALAURIE, Philippe, AYNÈS, Laurent. La famille. 3. éd., Paris: Defrénois, 2009.

PERDRIX, Louis. La garde d'autrui. Paris: L.G.D.J., 2010.

PEREIRA, Virgílio de Sá. Direito de Família. 3. ed. Rio de Janeiro: Forense, 2008.

RAUPP, Valdir. Senador-Relator. Parecer da Comissão de Constituição, Justiça e Cidadania, sobre o Projeto de Lei n. 117, de 2013, do Deputado Arnaldo Faria de Sá, que "altera os arts. 1.583, 1.584, 1.585, 1.596 e 1.634 da Lei n. 10.406, de 10 de janeiro de 2002 - Código Civil, para estabelecer o significado da expressão 'guarda compartilhada' e dispor sobre sua aplicação". Disponível em: $<$ http;//www.senado.gov.br/atividade/matéria/detalhes.asp?p_cod_mate=1 15668>. Acesso em 16.08.2015.

ROSENVALD, Nelson; FARIAS, Cristiano Chaves de. Curso de Direito Civil: Famílias. 7. ed. São Paulo: Atlas, 2015.

ROUDINESCO, Elisabeth. A família em desordem. Trad. André Telles. Rio de Janeiro: Jorge Zahar Editor, 2002.

ROUSSEAU, Jean-Jacques. Júlia ou A Nova Heloísa: Cartas de dois amantes de uma cidadezinha ao pé dos Alpes [Julie ou La Nouvelle Heloïse]. Trad. Fulvia M. L. Moretto. 2. ed. São Paulo: Hucitec, 2006. 
SILVA PEREIRA, Tânia da. O Melhor interesse da criança. In: SILVA PEREIRA, Tânia da (Coord.). O Melhor Interesse da Criança: um debate Interdisciplinar. Rio de Janeiro: Renovar, 1999:1-101.

TEPEDINO, Gustavo. Temas de direito civil. Rio de Janeiro: Renovar, 1999. 